\title{
Design and Marketing of Inns in Scenic Areas
}

\author{
Yinxiang Kong \\ School of Fine Arts \\ Huanggang Normal College \\ Huanggang, China
}

\begin{abstract}
The design and marketing of the inns in scenic areas is of great significance and effect to the inn's operators, which not just provides visitors with accommodation, but also contains more information, art, ideas, environment, and service and so on. Today, with increasingly intense competition of tourist market, no matter what kind of scenic areas and what kind of tourists, the inn operators need to provide them with a comfortable and pleasant living environment, consider how to attract more tourists using reasonable marketing knowledge and convey richer information.
\end{abstract}

Keywords—tourism; inn; design; marketing

\section{INTRODUCTION}

At present, tourism in China has become the most important way of leisure, international, with domestic and outbound tourism market of China continuing to grow steadily. Tourism in China is becoming the industry with huge scale, broad prospects and rapid growth. However, the rapid growth of tourism demand market also highlights many problems in the development of tourism and related industries in China. The development of domestic inn and hotel industry is relatively confusing. Although there are many inns, but can few can really provide the tourists with what they want most and what meet their psychological and aesthetic needs. It becomes one of the means of attracting tourists for inn operators to study the tourists and explore their true psychology to meet their needs, which allows tourists and inn operators to get win-win result.

\section{THE DESIGN REFLECTING THE LOCAL CHARACTERISTICS Allows CONSUMERS TO REMEMBER THE INN}

With the continuous improvement of the living standard of residents in China, people' requirements for the quality of life have become increasingly rich, and tourism has become the ordinary daily consumption of Chines residents. In the process of people participating in tourism consumption activities, the requirements for accommodation of tourism destination and other related product have become more diversified and personalized, but the traditional scenic inn can only meet the need of resting and living of tourists. With the improvement of tourist's living standards and cultural literacy and market competition, the pursuit of tourists for the art culture and leisure function of inns becomes higher. In order to better meet the diverse needs of tourists, the model of "tourist inn + " is chased after by travel operators, and achieves better returns in practice.

\section{A. Inns of Tourist Attractions should Understand the Psychological Factors of Tourists in order to Attract Tourists}

People like to pursue novel things. With vast land and rich historical heritage and cultural heritage, living habits and cultural differences of different regions and peoples in China are significantly different from each other. Out of curiosity and aspiration to knowledge, tourists come to the tourist destination to personally learn and feel the cultural connotation, observe and experience the novelty and mystery formed by differences between different regions and national cultures, which is the irresistible attraction for tourists brought by cultural tourism. The inns with local characteristics are more attractive, so that visitors can not only see the beauty but also live in such peculiar scenery, which is extremely enjoyable.

Most of the inns in tourist attractions are run by the way of homestay, mainly including personal operation and family operation. They are generally small, pursuing the home-like design and warm service, to make people feel the warmth of home and experience the exotic journey life different from home. The design of these inns brings together the local landscape environment and historic culture characteristics, absorbs the characteristics of the local traditional architecture and combines the design features of local ecology, customs, agriculture, forestry, fishery and other environment, to fully show the local characteristics, so that visitors can feel the unusual living environment.

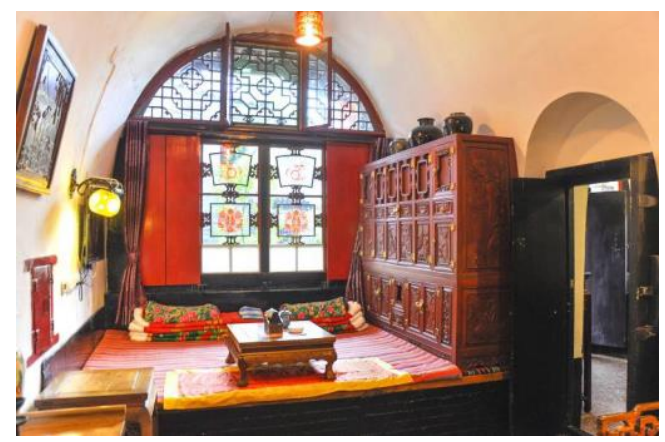

Fig. 1. Deluxe Suite of Guangxianyuan Inn in Pingyao, Shanxi. 
For example, the design of Guangxianyuan Inn of Pingyao as shown in "Fig. 1", Shanxi fully embodies the local characteristics. People of Shanxi have the habit of living in cave since ancient times, and for some tourists from southern China or other cities, it has a great temptation to live in cave. Guangxianyuan inn of Pingyao ancient city is formerly known as old house of Zhao, which was built in the Ming Dynasty, and was elegant and rich in ancient rhyme. This inn fully integrated the local regional features, which is designed into the cave style, and the interior decoration is also simple Chinese furniture unified with cave-style design. It integrates more local art features, and cave-style interior design style and the use of window grilles allow visitors to feel the beauty of the northern folk art at rest. The window grill is the folk art with strong northern style, which can let south tourists feel the very unique local characteristics adding the heatable adobe sleeping platform. Visitors can thus experience the primitive atmosphere that is completely different from that of the city.

\section{B. Integration of Diverse Culture in the Design of Inns Can Enrich Tourist Experience}

In the tourism process, visitors are also willing to experience and participate in richer cultural activities, and broaden their horizons, increase knowledge and feel the mental experience through exposure to cultural tourism venues or environment. Objectively, the tourists directly obtain knowledge information and spiritual education while in essence it is the perception of local cultural values, which creates a comprehensive pleasure experience of pursuing knowledge, beauty-appreciation and entertainment. For example, Yunzhongju Inn in Lushan Scenic Area, Jiangxi transforms the ordinary dwelling into a more distinctive inn, combining with the traditional and modern fashion style concept. The owner of this inn is a racing driver who loves dance, so in the design of the inn traditional wooden material are used as main building material, to endeavor to create an inn themed with racing and dance. The interior design is decorated with the clothes that the boss wore when racing and some honor certificates as in "Fig. 2" and "Fig. 3", which can make visitors feel the different cultural atmosphere, and design style different from that of other inns. They also provide racing training and set up a car club. In the spread of dance culture, they provide visitors with dance training activities. The interior design is simple and elegant Chinese traditional style, and the furniture is made of wood, which will give people a warm feeling to create the nostalghia atmosphere. The walls are decorated with the Chinese painting with a strong traditional style. At the same time, in order to meet the life sentiment of modern people, the inn is also equipped with a tea bar and bar, of which the decorative style is also the traditional Chinese style, so visitors can have a place for leisure after a day's tired travel as well as experience more cultural connotation. Wouldn't it be great? Only this kind of inn can give visitors a deep impression.

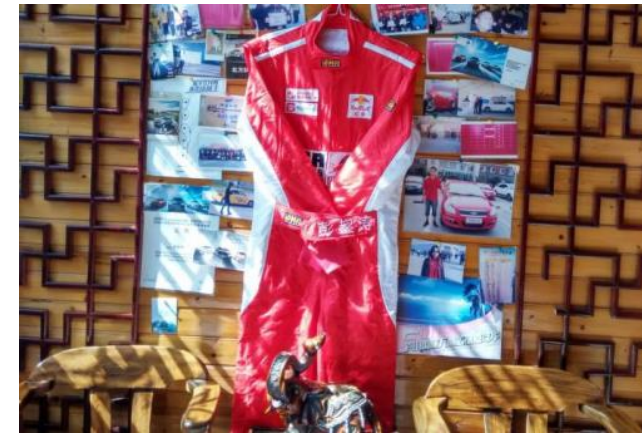

Fig. 2. Clothes of the boss.

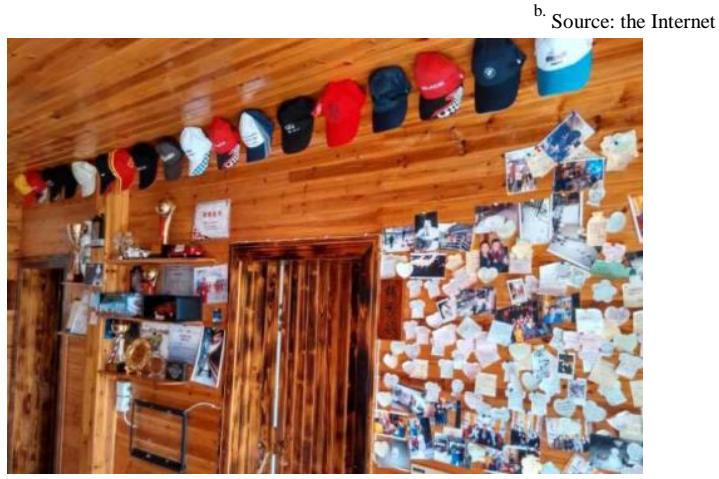

Fig. 3. Honor certificates of the boss.

c. Source: the Internet

\section{Building the Theme Culture Inn Can Attract Tourists with Special Cultural Hobby}

With the rapid increase in the number of inns in tourist attractions, choice for visitors becomes more and more. Most of the tourists regard the price as the most important conditions when selecting the inns, followed by districts and the living and decoration conditions of inns, but rare people take the artistic theme of inns as the basis for the choice, which on the contrary becomes an excellent business opportunities for the inns to integrate unique cultural and artistic connotation into the inn, so as to attract tourists with special cultural preferences because they have no other choice and will become a long-term repeat customers. For example, Yuanheyuan Budhism and Zen inn of Chengdu, located in the Wenshufang historic reservation in Qingyang District of Chengdu, is the first inn-style hotel that is themed with the culture of Buddha and Zen. The whole inn is a three-story small building, with the Chinese-style arched cornices as roof. The interior design is elegant, and mainly uses wood antique furniture. The inn adopts the traditional Chinese design style, with a statue of a Buddha placed in the middle of the courtyard. A large number of Buddhist paintings are hung on the walls around, and even the objects like table lamp are designed with Buddhist culture. Every detail such as incense boxes, tableware, tea sets, corridors, rooms, doors and windows embodies the Buddhist culture. In this way, visitors can be fully immersed in the realm of Buddhism, and do not want to leave. Thus they can get great 
satisfaction both from the psychological needs and visual needs.

In this era when consumer behavior becomes increasingly individualized and emotional, the consumption of tourists is not only the product itself, but the cultural and artistic symbolism attached to the product. Operators of inns must concerned about the customer experience needs from the perspective of experience economy, combine with history and regional culture, seriously inspect all aspects of operation, and strive to create unique and memorable tourism experience for customers.

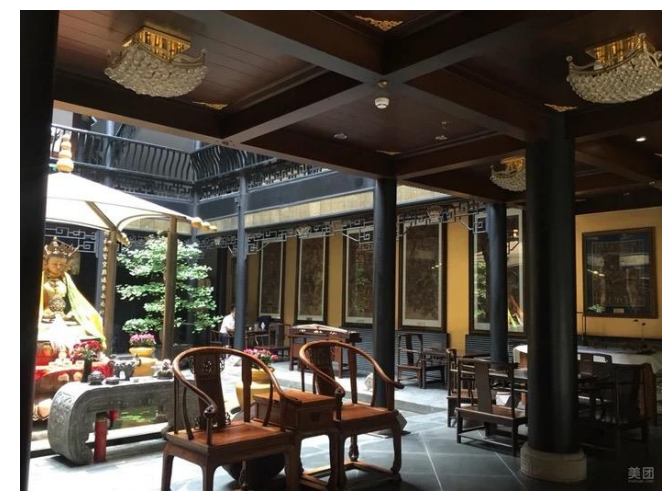

Fig. 4. Decoration in Yuanheyuan Budhism and Zen inn.

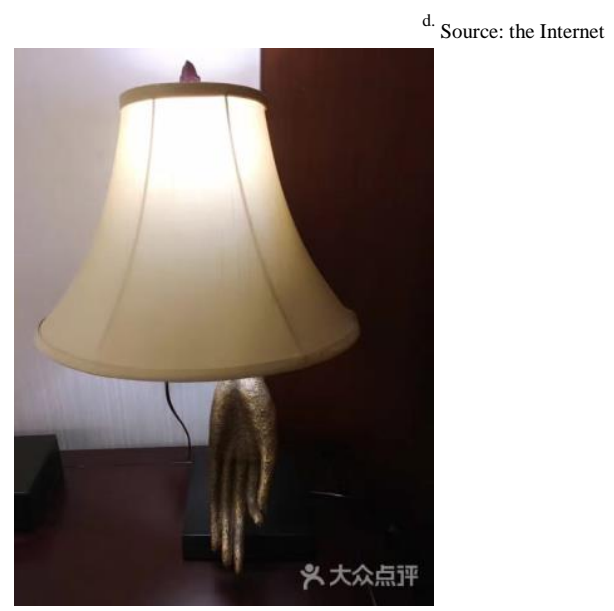

Fig. 5. Table lamp of Buddhist culture.

\section{UNIQUE SERVICE DESIGN IS AN IMPORTANT MEANS} TO ATTRACT TOURISTS

\section{A. Firstly, Different Services Should be Provided for Different Age Groups of Tourists}

As we know, it is the goal of marketing to meet the psychological needs of consumers. As the inns in scenic areas, in order to retain visitors, they must retain their hearts, so they need to fully understand the various psychological needs of tourists, and classify the tourists according to their age to analyze the psychology of different age groups of tourists. For instance, the tourists of 18 to 40 years old are mostly students and office workers busy with the career, so they have active thinking and the courage to challenge fresh and stimulus activities, and like adventure, but at the same time they have limited opportunities to travel due to busy work and life pressure. Therefore, some inns can meet their preferences in the design for these visitors by launching the design style of different themes in interior design, such as hammock room, water room, and animation themed room and so on. In the tourism activities, they can organize them to carry out some adventure activities and short-term experience activities, of course with safety guarantee. The psychological characteristics of this age group of tourists preferring difference, seeking something unique, pursuing something strange and new, and trying to find opportunities to express oneself. Basically, the tourists of 40 to 65 years have relaxed and stable live and work, with better economic capacity, and plenty of time for travel, so they can fully experience the beauty of scenic spots when traveling. For this age group of tourists, the inns can carry out some rich activities for them, such as singing party, cultural festival, painting and calligraphy festival, flower show, grape festival, opera festival, hand-made New Year paintings, kites and other crafts, making pottery and sculpture, which always take a long time and are more suitable for the needs of these tourists. These activities can greatly enrich their travel life, and give them a deep impression, making them the long-term repeat customers of the inn.

\section{B. Secondly, Design Different Activities according to the Different Occupations of Tourists}

They can carry out accommodation promotions in the annual holidays. For example, teachers can have free accommodation on Teachers' day (only the teachers enjoy free of charge, but they will bring a lot of tourists that can't enjoy the discounts), children under the age of 14 are free of charge on children's day, and the elderly over the age of 70 enjoy free of charge on Chung Yeung Festival. With the promotion of these activities, many accompanied ordinary tourists will be brought.

\section{CONCLUSION}

More and more modern tourists tend to pursue diversified experience, so inns in scenic areas need to provide with people a deep and unique cultural and artistic experience and high quality aesthetic accommodation, so that visitors can feel cultural experience activities and perception with deep regional characteristics. They can move the tourist with spatial environment with characteristic cultural connotation to integrate them into and touch the hearts of tourists, so that visitors can generate resonance with the environment and culture. Thus they are willing to pay several times or even ten times cost. Therefore, the trend that visitors are willing to pay high price for spiritual enjoyment makes it possible for inns to get high added-value.

\section{REFERENCES}

[1] Sun Min. Image Design of Chinese Modern Commercial Store. Hube University of Technology, 2010.5. 
[2] Xie Gang. A Study on the Marketing Strategy of Cultural Tourism in Chuzhou. Anhui University, 2016.4.

[3] Sun Guang. design and marketing of commercial store Tianjin University of Technology, 2012.3.

[4] Yu Yixian. A Study on the Cultural Marketing Strategy of Modern Tea House in China. Chengdu Textile College, 2016.3.

[5] Zhang Aihong. A Study on the Color Design of Tourism Art Derivatives under the Perceptual Consumption. Journal of Guizhou University (Artist Edition). 2014.6

[6] Wang Linrun. Research on Interior Design and Marketization 。 Dalian Polytechnic University, 2010.4.

[7] Wang Yingying. A Study on the Inheritance and Development of Design of Traditional dwellings and homestay in Henan. Henan Institute of Engineering, Art Science and Technology

[8] Zhang Yu. A Study on the experience Marketing Strategy of Folklore Inn - Taking Pingyao as an Example. Taiyuan University, marketing strategy, 2011.10

[9] Song Peng, Xiao Xiao, Cui Jiachun. The Application of "crowdsourcing" Theory in Tourism Enterprise Marketing - Taking the Yuanhe Yuan Buddha and Zen Inn of Chengdu as an Example. Chengdu University of Technology, 2010.11. 